\title{
Allowing for heterogeneity in the decomposition of measures of inequality in health
}

\author{
by \\ Andrew M. Jones ${ }^{\mathrm{a}}$ and Ángel López Nicolás*b,c
}

October 2004, revised June 2005

\author{
a Department of Economics and Related Studies, University of York, York YO10 5DD, UK \\ b Departament d'Economia i Empresa and CRES, Universitat Pompeu Fabra, 08005-Barcelona, Spain \\ c Departamento de Economía, Universidad Politécnica de Cartagena, 30203-Cartagena, Spain
}

\begin{abstract}
This paper shows how recently developed regression-based methods for the decomposition of health inequality can be extended to incorporate heterogeneity in the responses of health to the explanatory variables. We illustrate our method with an application to the GHQ measure of psychological well-being taken from the British Household Panel Survey. The results suggest that there is an important degree of heterogeneity in the association of health to explanatory variables across birth cohorts and genders which, in turn, accounts for a substantial percentage of the inequality in observed health.
\end{abstract}

JEL classification: D63, I12, C21

Keywords: Health inequalities; heterogeneity; decomposition analysis; panel data.

* Corresponding author. Fax:+34 968325781. E-mail: angel.lopez@upct.es Data from the British Household Panel Survey (BHPS) were supplied by the ESRC Data Archive. Neither the original collectors of the data nor the Archive bear any responsibility for the analysis or interpretations presented here. This chapter derives from the project "The dynamics of income, health and inequality over the lifecycle" (known as the ECuity III Project), which is funded in part by the European Community's Quality of Life and Management of Living Resources programme (contract QLK6-CT-2002-02297) and the project "La dinámica del estado de salud y los factores socieconómicos a lo largo del ciclo vital. Implicaciones para las políticas públicas", which is supported by the Fundación BBVA. We are grateful to the EC and to the Fundación BBVA and the Spanish Ministry of Education (projects BEC2002-04294-C02-02 and SEJ2005-09104-C02-02) for financial support. We thank Eddy van Doorslaer for support and advice and to participants at the York Seminars in Health Econometrics (YSHE) for their comments. We gratefully acknowledge the comments and suggestions of two anonymous referees and the editor of this journal. 


\section{Introduction}

Health economists have adopted the Gini coefficient and concentration indices to provide summary measures of inequalities of health within populations (see e.g. Silber, 1988, Wagstaff et al, 1989, 1991, 1994, and van Doorslaer et al. 1997). Like the Gini coefficient of income inequality, the Gini and concentration indices for health have the attraction that they can be decomposed by factors (see e.g., Rao, 1969, Kakwani, 1980). A recent contribution by Wagstaff et al. (2003) has used this property to show how a linear regression approach can be used to decompose these indices into the contributions of different explanatory variables. In this regression-based decomposition the contribution of each factor to overall inequality depends on the elasticity of health with respect to that variable, capturing the health gradient, and on the concentration index for the factor, capturing how much inequality there is in the distribution of the factor itself. Van Doorslaer and Koolman (2004) apply the regression-based decomposition to data from the European Community Household Panel (ECHP). They find that Portugal, the UK and Denmark have a high degree of such health inequality, while the Netherlands, Germany, Italy, Belgium, Spain, Austria and Ireland show lower levels of health inequality. The decomposition of these crosscountry differences according to differences in inequalities and elasticities of the factors reveals a striking pattern that the difference in elasticities across countries plays a much greater role than differences in the distribution of factors. Van Doorslaer and Koolman (2004) argue that these empirical results have important policy implications, implying that reducing health inequalities is likely to be more amenable to health policy, that operates on the health-gradient, than to fiscal policy, that operates on income redistribution.

The decomposition proposed by Wagstaff et al. (2003) and applied by van Doorslaer and Koolman (2004) and others treats individual responses to the explanatory variables (the regression slope coefficients) as homogeneous across individuals. However, in reality, there is likely to be heterogeneity in individual responses. For example, in his Nobel Lecture Heckman (2001) argues that one of the contributions of microeconometrics to economic knowledge has been to establish 
as an empirical regularity that economic behaviour is diverse, and that traditional econometric models failed to account for such heterogeneity:

"..the most important discovery was the evidence on the pervasiveness of heterogeneity and diversity in economic life...In the context of regression analysis not only were intercepts variable but so were the slope cefficients." Heckman (2001, p.674).

To account for this we propose a method that deals with heterogeneity, while retaining the useful summary information provided by the regression-based decomposition approach. We show how the decomposition can be extended to allow for heterogeneity in the responses. We illustrate the method with an application to the measurement of inequality in the GHQ measure of psychological well-being using data from the British Household Panel Survey (BHPS) for 1991-99. The empirical results for the GHQ measure of psychological well-being suggest that there is an important degree of heterogeneity in the association of health to explanatory variables across birth cohorts and genders which, in turn, accounts for a substantial percentage of the inequality in observed health.

The structure of the paper is the following. Section 2 presents our main result and we show how the decomposition of the Gini index and the concentration indices into the contributions of different explanatory variables in a regression model can be modified to incorporate individual heterogeneity in all the coefficients. Section 3 discusses the main features of the BHPS data set and presents and discusses the estimates from regression models for GHQ that allow for heterogeneous responses across age and gender cohorts. Section 4 concludes.

\section{Regression based decompositions of inequality}

The departure point for our methodology is the decomposition of inequality measures into the contributions of different explanatory variables by means of a linear regression model (see e.g., Wagstaff et al., 2003). This branch of the literature stems from the general interest in being able to decompose relevant features of a distribution into explanatory factors, some of which may be policy amenable (see e.g. Kolenikov and Shorrocks, 2005, and Shorrocks, 1999, for a method that decomposes changes in poverty rates using the Shapley decomposition method from game theory). The Wagstaff et al. (2003) approach applies to both the Gini coefficient for overall health inequality and the concentration index for income-related health inequality. The health Gini was proposed by LeGrand (1989) and discussed by Wagstaff et al. (1991) who also advocated the use of concentration indices for income-related health inequality (Wagstaff et al., 1989). Many health economists have concentrated their attention on socioeconomic inequalities in health, in particular, 
income-related inequalities (see e.g., Wagstaff et al., 1989; van Doorslaer and Koolman, 2004). Others have argued that this can be too narrow and that there should be a broader focus on all sources of health inequality, not just those related to income (see e.g., Gakidou et al., 2001; Fleurbaey, 2004). However van Doorslaer and Jones (2003) point out that, within the framework used here, it is straightforward to move between the two concepts as the Gini coefficient for total health inequality is proportional to the concentration index for income-related health inequality (see van Doorslaer and Jones, 2003, p.70). In their empirical analysis with Canadian data they find that income-related inequality accounts for around 40 per cent of total health inequality. It is increasingly common for empirical studies to report the results of regression-based decompositions for both Gini and concentration indices (see van Doorslaer and Jones, 2003; Morris et al., 2003). This is the strategy we adopt in this paper.

Suppose we are interested in calculating the Gini coefficient for a measure of health using individual data in a sample from the population of interest. Let $y_{i}$ denote a measure of health for the $i^{\text {th }}$ individual, $i=1,2, \ldots N$, and $R_{i}$ denote the cumulative proportion of the population ranked by $\mathrm{yi}_{\mathrm{i}}$ up to the $\mathrm{i}^{\text {th }}$ individual (their 'relative rank'). Ignoring, for expositional purposes, the fact that in general sampling weights will be necessary, the Gini coefficient, G, for health is given by (see e.g., Lambert, 1994 p.43),

$$
G=\left(\frac{2}{\bar{y}}\right) \operatorname{cov}\left(y_{i}, R_{i}\right)
$$

where $\bar{y}=E\left(y_{i}\right)$. Now let $\mathrm{y}_{\mathrm{i}}$ be given by the following linear regression model

$$
y_{i}=\beta_{1}+\sum_{k=2}^{K} \beta_{k} x_{k i}+\varepsilon_{i}
$$

where $\mathrm{k}$ is the number of regressors $(x)$. By substituting this for $\mathrm{y}_{\mathrm{i}}$, the Gini index of $\mathrm{y}$ can be written as (see Wagstaff et al., 2003),

$$
G=\sum_{k=2}^{K}\left(\beta_{k} \frac{\bar{x}_{k}}{\bar{y}}\right) C_{k}+\left(\frac{2}{\bar{y}}\right) \operatorname{cov}\left(\varepsilon_{i}, R_{i}\right)
$$


The first term in brackets is the elasticity of $\mathrm{y}$ with respect to $\mathrm{x}_{\mathrm{k}}$ evaluated at the sample means $\left(\bar{x}_{k}\right.$ and $\bar{y}$ ), and $\mathrm{C}_{\mathrm{k}}$ is the concentration index of $\mathrm{x}_{\mathrm{k}}$ on $\mathrm{y}$. The latter expression can be easily modified to obtain the concentration index of y against another variable of interest. For instance, the concentration index, CI, of health against income would be computed according to

$$
C I=\sum_{k=2}^{K}\left(\beta_{k} \frac{\bar{x}_{k}}{\bar{y}}\right) C^{\prime}{ }_{k}+\left(\frac{2}{\bar{y}}\right) \operatorname{cov}\left(\varepsilon_{i}, R^{\prime}{ }_{i}\right)
$$

where $C_{k}$ denotes the concentration index of $x_{k}$ against income and $R_{i}$ is the cumulative proportion of the population ranked by income up to the $i^{\text {th }}$ individual. These decomposition formulae are related to the methods that come from the "factor components" literature as reviewed by Fields (2003). In fact, by setting the constant term equal to zero, the rest of beta coefficients equal to unity and the error term equal to zero in equation 2 , it is straightforward to show that the Gini (or the concentration index) for any variable resulting from a sum of "factors" (e.g. total income as a sum of, say, labour income plus capital income) can be written as a weighted sum of the concentration indices of each of the constituent factors, with weights equal to the share of each factor over the aggregate (Rao, 1969; Kakwani, 1980). So, if total income is a sum of labour income plus capital income, then the Gini coefficient of total income is the sum of the concentration indices of labour income on total income and capital income on total income, each weighted by their share of total income in the population (see Fields 2003).

In practice, the decomposition formulas, (3) and (4), are applied using least squares estimates of the $\beta s$ and of the residuals. Thus these inequality measures can be decomposed into an "explained part" and an "unexplained part" (see Wagstaff et al., 2003). The "explained" part can be usefully broken down into the contributions of individual explanatory variables. As for the "unexplained" part, it is a scaled measure of the covariance of the residuals in the regression model with the position of the individual in the distribution of the variable of interest. As such, the unexplained part should be zero if the regression model for the measure of health is specified in a way such that there is no systematic variation in unobserved heterogeneity in health according to the position of the individual in the distribution of the relevant variable. So, the contribution of the residuals should be close to zero for the concentration index but may be quite large for the Gini coefficient.

The presence of heterogeneity in econometric models for microdata, as reflected by low coefficients of determination, would lead to the suspicion that a regression specification that 
assumes homogeneous responses may not capture all the variation in $\mathrm{y}$. A very general way to allow for individual heterogeneity is by means of a regression model for the health variable with heterogeneous parameters. Thus, the regression model can be modified to yield,

$$
y_{i}=\beta_{i 1}+\sum_{k=2}^{K} \beta_{i k} x_{k i}+u_{i}
$$

where all the parameters in the model are individual specific. Equation (5) introduces heterogeneity through a linear specification. For ease of interpretation the model can be re-written in the form,

$$
\begin{aligned}
& y_{i}=\beta_{1}+\sum_{k=2}^{K} \beta_{k} x_{k i}+\left(\beta_{i 1}-\beta_{1}\right)+\sum_{k=2}^{K}\left(\beta_{i k}-\beta_{k}\right) x_{k i}+u_{i} \\
& =\beta_{1}+\sum_{k=2}^{K} \beta_{k} x_{k i}+v_{i}
\end{aligned}
$$

where $\beta_{k}=E\left(\beta_{i k}\right)$. Assuming conditional independence of the $\beta$ s and the elements of $x$, such that $E\left(\beta_{i k} \mid x_{i}\right)=E\left(\beta_{i k}\right)=\beta_{k}$ for all $k=1, \ldots K$, gives a random parameters specification and implies linear scale heteroscedasticity in $v_{i}$ (see, Koenker and Bassett (1982)). This need not be too restrictive as the regressors, $x$, may contain high order polynomials, interactions and other transformations of the variables of interest. Koenker and Bassett (1982, p.45) show that the "linear scale model of heteroscedasticity is an important special case of the general class of models with linear conditional quantile functions. It subsumes many models of systematic heteroscedasticity that have appeared in the econometrics literature". If conditional independence of the $\beta$ s and the elements of $x$ does not hold, the model leads to a correlated/fixed parameters specification which can be estimated by introducing an individual-specific dummy variable $d_{i}, i=1, \ldots, n$, (by analogy with the least squares dummy variable estimator for the fixed effects model),

$$
y_{i}=\sum_{i=1}^{n} \beta_{i 1} d_{i}+\sum_{i=1}^{n} \sum_{k=2}^{K} \beta_{i k} d_{i} x_{k i}+u_{i}
$$

So, estimation of the $\beta_{\mathrm{i}}$ s would require a long panel data set with sufficient time series variation to estimate a separate regression for each individual. In our empirical application we allow for heterogeneity across age-gender cohorts and estimate separate regressions for each group.

Substituting equation (5) into (1) we obtain, 


$$
\begin{aligned}
G & =\left(\frac{2}{\bar{y}}\right) \operatorname{cov}\left(y_{i}, R_{i}\right)= \\
G & =\left(\frac{2}{N \bar{y}}\right) \sum_{i}\left(y_{i}-\bar{y}\right)\left(R_{i}-1 / 2\right)= \\
G & =\left(\frac{2}{N \bar{y}}\right) \sum_{i}\left(\beta_{i 1}+\sum_{k=2}^{K} \beta_{i k} x_{k i}-\bar{y}\right)\left(R_{i}-1 / 2\right)+\left(\frac{2}{\bar{y}}\right) \operatorname{Cov}\left(u_{i}, R_{i}\right)
\end{aligned}
$$

To provide a benchmark for our decomposition analysis, consider estimating a "pooled" regression that treats $\beta_{i}$ s as constant and ignores the individual heterogeneity. Since,

$$
\bar{y}=\beta_{1}^{O L S}+\sum_{k=2}^{K} \beta_{k}^{O L S} \bar{x}_{k}
$$

where $\beta$ oLS denotes the OLS estimates of the coefficients from the pooled model, we can write after some manipulation,

$G=\left(\frac{2}{N y}\right)\left[\sum_{i}\left(\sum_{k=2}^{K} \beta_{k}^{O L S}\left(x_{i k}-\bar{x}_{k}\right)+\sum_{k=2}^{K}\left(\beta_{i k}-\beta_{k}^{O L S}\right) x_{i k}+\left(\beta_{i 1}-\beta_{1}^{O L S}\right)\right)\left(R_{i}-1 / 2\right)\right]+\left(\frac{2}{\bar{y}}\right) \operatorname{Cov}\left(u_{i}, R_{i}\right)$

Collecting terms and changing the order of summation,

$$
\begin{aligned}
& G=\sum_{k=2}^{K}\left(\frac{2}{\bar{y} N}\right) \beta_{k}^{O L S} \sum_{i}\left(x_{i k}-\bar{x}_{k}\right)\left(R_{i}-1 / 2\right)+ \\
& +\left(\frac{2}{\bar{y} N}\right) \sum_{k=2}^{K} \sum_{i} x_{i k}\left(\beta_{i k}-\beta_{k}^{O L S}\right)\left(R_{i}-1 / 2\right)+ \\
& +\left(\frac{2}{\bar{y} N}\right) \sum_{i}\left(\beta_{i 1}-\beta_{k}^{O L S}\right)\left(R_{i}-1 / 2\right)+\left(\frac{2}{\bar{y}}\right) \operatorname{Cov}\left(u_{i}, R_{i}\right)
\end{aligned}
$$

Noting that the concentration index of $\mathrm{x}_{\mathrm{k}}$ on $\mathrm{y}$ is given by,

$$
C_{k}=\frac{2}{\bar{x}_{k}} \operatorname{cov}\left(x_{i k}, R_{i}\right)
$$

And considering $\beta_{1}$ OLS a measure of central tendency for $\beta_{\mathrm{i} 1}$, we finally obtain, 


$$
\begin{aligned}
& G=\sum_{k=2}^{K} \beta_{k}^{\text {OLS }} \frac{\bar{x}_{k}}{\bar{y}} C_{k}+\left(\frac{2}{\bar{y} N}\right) \sum_{k=2}^{K} \sum_{i} x_{i k}\left(\beta_{i k}-\beta_{k}^{O L S}\right)\left(R_{i}-1 / 2\right)+ \\
& +\left(\frac{2}{\bar{y}}\right) \operatorname{cov}\left(\beta_{i 1}, R_{i}\right)+\left(\frac{2}{\bar{y}}\right) \operatorname{Cov}\left(u_{i}, R_{i}\right)
\end{aligned}
$$

The first term of this equation is exactly the same as the first term in equation (3) when model (2) is estimated by OLS. The residual term in equation (3) is now split into three components given by the second, third and fourth terms in equation (6). The second term is the contribution to overall inequality of the covariance (weighted by the values of $\mathrm{x}_{\mathrm{k}}$ ) of the slope parameters with the health rank. The third term is simply the covariance of the intercepts (centred at the OLS intercept coefficient) with the health rank. The fourth term corresponds to the "unexplained part" component associated to the model in equation 5. The interpretation of the new decomposition formula has a clear parallel with the use of Oaxaca-type decompositions of changes in inequalities over time or across countries, based on the comparison of two different samples (see Wagstaff et al., 2003). The Oaxaca (1973) decomposition allows an analysis of the extent to which changes in inequality are attributable to changes in inequality in the regressors and to changes in their associated elasticities. Similarly, our new decomposition of the overall level of inequality distinguishes between the contribution of the level of inequality in the regressors, evaluated at the pooled level of the coefficients, and the contribution of heterogeneity in the coefficients around the pooled values.

Like the Gini coefficient, the concentration index for health can be written as,

$$
\begin{aligned}
& C I=\sum_{k=2}^{K} \beta_{k}^{O L S} \frac{\bar{x}_{k}}{\bar{y}} C_{k}+\left(\frac{2}{\bar{y} N}\right) \sum_{k=2}^{K} \sum_{i} x_{i k}\left(\beta_{i k}-\beta_{k}^{O L S}\right)\left(R_{i}^{\prime}-1 / 2\right)+ \\
& +\left(\frac{2}{\bar{y}}\right) \operatorname{cov}\left(\beta_{i 1}, R_{i}^{\prime}\right)+\left(\frac{2}{\bar{y}}\right) \operatorname{Cov}\left(u_{i}, R_{i}^{\prime}\right)
\end{aligned}
$$

Each component has a similar interpretation to the Gini coefficient, with health rank, R, replaced by income rank, R'. The first term is identical to the first term in (4) and the second two terms decompose the generalised concentration index of the residual, allowing for heterogeneity. 
Implementation of the decomposition formulas in (6) and (7) requires individual-specific estimates of the intercepts and slope coefficients $\left(\beta_{i}\right)$. Panel data, such as the BHPS, provides the greatest scope for identifying these parameters. The $\beta_{i}$ 's could be retrieved from a random parameters specification or, given sufficient time series variation, they could be estimated in a fixed effects specification with individual-specific slopes as well as intercepts. In practice, identifying individualspecific $\beta$ 's from a relatively short time series is problematic. So, for our illustrative empirical application, we allow for heterogeneity in responses across fourteen groups of individuals, defined by age-gender cohorts 


\section{An empirical application}

\subsection{The BHPS data}

To illustrate the methods proposed above we estimate a model of psychological well-being based on scores from the General Health Questionnaire (GHQ) as measured in the British Household Panel Survey (BHPS). This application was chosen because the BHPS (see Taylor et al., 1998 for details about sampling etc.) is a recent panel data set with good quality income and socio-economic variables and because the GHQ measure can be modelled conveniently in a linear regression framework (see e.g., Hauck and Rice, 2003; Wildman, 2003). We use nine waves of data (19911999 ) in order to be able to estimate a health function for different population groups.

For our illustrative application, we first select individuals who had at least one interview at any of the nine waves, between 1991 and 1999. Selecting the unbalanced cases gives an initial sub-sample of 95,601 observations corresponding to 21,817 individuals. From these we have dropped the observations containing missing values in the GHQ score (5,853 observations) and those whose full household income is reported to be either below $£ 2000$ or above $£ 77,000$, or is missing (1010 observations). These income thresholds correspond to less than $1 \%$ of the observations in the extreme left and right hand tails of the distributions. A further 583 observations with missing values for marital status, social class, job status, number of children or education are dropped from the sample. Thus the estimating sample contain 88155 observations. We then group these observations according to age cohort and gender resulting in 14 different subsamples as shown in Table 1. For our illustrative purposes it would have been possible to define demographic groups according to other variables. However, since age cohort and gender are exogenous to mental health, our choice guarantees that there is no endogenous selection into any of the sub-samples. This cannot be guaranteed with groupings based on education, say, since investment in education is generally positively associated to good health. 
Table 1. Sub-sample sizes by age cohort and gender

\begin{tabular}{clc} 
Group & \multicolumn{1}{c}{ Cohort/gender } & $\mathrm{N}$ \\
\hline 1 & Born1976-1983 (women) & 3321 \\
2 & Born1976-1983 (men) & 2893 \\
3 & Born1965-1975 (women) & 9642 \\
4 & Born1965-1975 (men) & 8908 \\
5 & Born1955-1964 (women) & 9425 \\
6 & Born1955-1964 (men) & 8323 \\
7 & Born1945-1954 (women) & 8357 \\
8 & Born1945-1954 (men) & 7054 \\
9 & Born1935-1944 (women) & 5901 \\
10 & Born1935-1944 (men) & 5269 \\
11 & Born1925-1934 (women) & 5026 \\
12 & Born1925-1934 (men) & 4341 \\
13 & Born before 1925 (women) & 5897 \\
14 & Born before 1925 (men) & 3798 \\
\hline \hline Total & & 88155 \\
\hline
\end{tabular}

The BHPS self-completion questionnaire incorporates a reduced version of the General Household Questionnaire (Goldberg and Williams, 1988; Bowling, 1991). The GHQ was developed as a screening instrument for psychiatric illness and is now often used as an indicator of psychological well-being (Hauck and Rice, 2003; Weich et al., 2001; Wildman, 2003). The shortened GHQ includes 12 elements: concentration, sleep loss due to worry, perception of role, capability in decision making, whether constantly under strain, perception of problems in overcoming difficulties, enjoyment of day-to-day activities, ability to face problems, loss of confidence, selfworth, general happiness, and whether suffering depression or unhappiness. Responses are given on a 4-point scale ranging from 0 to 3 , with 0 being the best score. For our dependent variable we use the Likert scale, which sums the individual components (Likert, 1952). This gives an overall scale that runs from 0 to 36 . To make the interpretation of results more intuitive, we have re-scaled this measure in order to make it increasing in good health. Therefore we use GHQ'=36-GHQ rather than the original GHQ score. 


\subsection{A model with heterogeneous responses for the GHQ score}

Next we use a regression model for the level of GHQ' score allowing for heterogeneous responses by age cohort and gender. The intention of the regression model is simply to capture the linear association between the expected GHQ' score and a range of socio-economic characteristics while allowing for differential responses according to demographic group. It should not be taken as a structural model or used to infer a direction of causality. It should also be noted that we do not investigate the structure of individual heterogeneity within each of the age cohort and gender groups. In principle, it would be possible to specify error component models (either fixed or random individual effects) for each of the population groups, and the decomposition analysis of equations (6) and (7) would be fully applicable. However, given the illustrative nature of the empirical exercise, we simply opt for a specification that allows for intra-individual temporal dependence of an unknown form in the error terms. As with the random effects model, the intraindividual dependence in the error terms in this specification requires adjusting the covariance matrix of the estimates.

Table 2 gives the names and definitions of the regressors and their means for the pooled samples of men and women.

Table 2 Definitions and means for the explanatory variables

\begin{tabular}{|c|c|c|c|}
\hline Var. Name & Definition & Women & Men \\
\hline $\log ($ income) & Logarithm of equivalised annual real household income & 9.13 & 9.26 \\
\hline Never married & 1 if never married, 0 otherwise & 0.18 & 0.23 \\
\hline Divced., septed., or widwd. & 1. 1 if divorced, separated or widowed, 0 otherwise & 0.20 & 0.08 \\
\hline Children & Number of children in household & 0.63 & 0.59 \\
\hline Professional or managerial & 1 if R. General's SC is prof., manag. or technical occupation, 0 otherwise & 0.17 & 0.26 \\
\hline Skilled & 1 if R. General's SC is skilled manual occupation, 0 otherwise & 0.05 & 0.21 \\
\hline Other SC & 1 if R. General's SC is other, 0 otherwise & 0.54 & 0.42 \\
\hline Unskilled & 1 if R.General's SC is partly skilled or unskilled occupation, 0 otherwise & 0.03 & 0.02 \\
\hline Unemployed & 1 if unemployed, 0 otherwise & 0.03 & 0.06 \\
\hline Student or retired & 1 if student or retired & 0.25 & 0.23 \\
\hline Carer & 1 if family carer, 0 otherwise & 0.15 & 0.01 \\
\hline Degree & 1 if highest academic qualification is degree or higher degree, 0 otherwise & 0.10 & 0.13 \\
\hline $\mathrm{HND} / \mathrm{HNCT}$ & 1 if highest academic qualification is HND or HNCT, 0 otherwise & 0.06 & 0.07 \\
\hline $\mathrm{O} / \mathrm{CSE}$ & 1 if highest academic qualification is $\mathrm{O}$ level or CSE, 0 otherwise & 0.31 & 0.28 \\
\hline No qualification & 1 if no academic qualifications, 0 otherwise & 0.38 & 0.32 \\
\hline Non-white & 1 if ethnic origin is other than white, 0 otherwise & 0.03 & 0.03 \\
\hline $\mathrm{N}$ & & 47569 & 40586 \\
\hline
\end{tabular}


Full details of the regression results are given in a table in the Appendix. The coefficients are presented along with the Huber-White robust standard errors that are adjusted for clustering within-individuals. The first column presents the estimates for a model where all parameters are restricted to be equal across demographic groups and where a cubic in age and a gender dummy have been included. The following 14 columns (column 1 corresponds to group 1 as defined in Table 1 and so on) present the estimates for the model where all parameters are allowed to vary. While the RESET statistic at the bottom of the pooled model clearly suggests misspecification, the test values for the group-specific models are much lower and in several cases are well below standard critical values. In order to investigate the potential sources of misspecification, a quadratic term in the logarithm of income was included in alternative specifications for both the pooled model and the group specific models but it was not significant in any of the cases. This would favour the view that misspecification is more related to the assumption of common structure than incorrect functional form, suggesting that even finer grouping would lead to more improvements in the RESET statistics. Further evidence against the assumption of common responses is provided in the last column by the F statistic for the null of homogeneity across groups, which is well above standard critical values for the overwhelming majority of regressors.

The estimates reveal a rich pattern of heterogeneity across groups. Notably, while the marginal effect of equivalised household income is statistically insignificant for men and women in both the youngest age cohort (born between 1976-1983) and the oldest age cohorts (born before 1925), it takes a significantly positive value for all other cohorts and, for both men and women, reaches its maximum value for the 1935-1944 and 1945-1954 cohorts. Being "Divorced, separated or widowed" is associated with a lower GHQ' score than the omitted category (living as a couple), and while its effect tends to be greater in absolute value for men in younger cohorts, this event tends to have a greater negative impact on women in cohorts born before 1955. Unskilled women in older cohorts tend to report a greater GHQ' score than skilled non-manual workers (the omitted occupational category) in the same cohorts, but this effect is insignificant for the rest of demographic groups. All individuals within the "other social class" occupational category tend to report a lower GHQ' score than skilled non-manual workers within their group, but the association is stronger in old cohorts, and within the latter the effect is greater in absolute value for males. Unemployed women belonging to the 1945-1954 cohort or younger report a significantly lower GHQ' score than those in employment (the omitted labour status category) in the same cohorts. A similar pattern is found for men belonging to the 1955-1964 cohort or younger. The "student or retired" dummy attempts to capture the effect of (labour) inactivity, in relation to the employed 
default category (it is important to bear in mind that for cohorts born after 1954, the majority of cases are students, whereas for cohorts born before 1945 the majority of cases are retirees.) The estimates reveal that retirees born before 1945 report a higher GHQ' score that the default category. Being a family carer is associated to a lower GHQ' score than being employed in the youngest female cohort, while men in the 1935-1944 cohort in family care tend to report a greater GHQ' score. Women with degrees or no qualifications in the youngest cohort report on average a greater GHQ' score than women with A-levels (the omitted educational category) in the same cohort. But having no qualifications is associated to a lower GHQ' score for women born between 1955-1975 and between 1925-1934 and men born between 1955-1964 and between 1925-1934. Within the 1925-1934 cohort of men, those with A levels tend to report the greatest GHQ' score. On the other hand, within the 1935-1944 cohort, both men and women with O levels tend to report a greater GHQ' score than, respectively, men and women with A levels. The intercept terms also reveal an interesting pattern of heterogeneity: Intercepts for young cohorts tend to be greater than those of old cohorts and, also, within all but the 1935-1944 cohort, the intercept for males is greater than for females.

\section{3 Decomposition analysis}

The heterogeneity of the effects discussed above has an impact on the decomposition of the inequality measures, as shown in section 2 . We now use these parameter estimates in order to calculate and decompose the Gini coefficient and concentration indices for the GHQ' score in the 1999 wave of the BHPS. Table 3 presents, for each explanatory variable in the model, the results for the decomposition of both inequality indices into:

i) The "homogeneous parameters contribution": i.e. the contribution of the product of the elasticities evaluated at the homogeneous parameters and the concentration indices of the regressors on health rank (or income rank in the case of the $\mathrm{CI}$ ),

ii) "Heterogeneous parameters contribution": i.e. the contribution of the covariance of the heterogeneous parameters with the health rank (or income rank in the case of the CI),

Recall the expressions for the decompositions of the Gini coefficient and the concentration index in (6) and (7). As demonstrated by Wagstaff et al. (2003), the "homogeneous parameters contributions" depend on the product of the elasticity of health with respect to each explanatory variable and the concentration index for each variable, which in turn depend on the scaled covariance between the variable and the relative rank of health or income. The "homogeneous 
parameters" component treats the elasticity as homogeneous across individuals as it is evaluated at the OLS estimation of $\beta_{\mathrm{k}}$ and the means of $\mathrm{y}$ and $\mathrm{x}_{\mathrm{k}}$. In Table 3 the "homogeneous parameters contributions" account for $3.20 \%$ of the observed Gini coefficient and $86.54 \%$ of the concentration index of health on income. The stark contrast between the ability of the regression model to "explain" total inequality and income-related inequality in the GHQ' score reflects the fact that income-related inequality, measured by C, accounts for only 11 per cent of total inequality, measured by $G$. 
Table 3. Contribution of explanatory variables to inequality indices

\begin{tabular}{|c|c|c|c|c|c|c|}
\hline GINI INDEX & \multicolumn{2}{|c|}{ Hom. contrib. } & \multicolumn{2}{|c|}{ Het. contrib. } & \multicolumn{2}{|c|}{ Total contrib. } \\
\hline Log(income) & 0,00069 & $0,61 \%$ & $-0,00375$ & $-3,29 \%$ & $-0,00306$ & $-2,68 \%$ \\
\hline Never married & 0,00023 & $0,20 \%$ & $-0,00039$ & $-0,34 \%$ & $-0,00016$ & $-0,14 \%$ \\
\hline Divced., septed., or widwd. & 0,00084 & $0,74 \%$ & 0,00005 & $0,04 \%$ & 0,00089 & $0,79 \%$ \\
\hline Children & 0,00002 & $0,02 \%$ & 0,00011 & $0,09 \%$ & 0,00013 & $0,11 \%$ \\
\hline Professional or managerial & 0,00002 & $0,02 \%$ & 0,00007 & $0,06 \%$ & 0,00009 & $0,08 \%$ \\
\hline Skilled & 0,00051 & $0,45 \%$ & $-0,00032$ & $-0,28 \%$ & 0,00019 & $0,17 \%$ \\
\hline Unskilled & 0,00004 & $0,03 \%$ & $-0,00004$ & $-0,03 \%$ & 0,00000 & $0,00 \%$ \\
\hline Unemployed & 0,00014 & $0,12 \%$ & 0,00012 & $0,11 \%$ & 0,00026 & $0,23 \%$ \\
\hline Student or retired & 0,00024 & $0,21 \%$ & $-0,00023$ & $-0,20 \%$ & 0,00001 & $0,01 \%$ \\
\hline Carer & 0,00011 & $0,09 \%$ & $-0,00010$ & $-0,09 \%$ & 0,00001 & $0,01 \%$ \\
\hline Other SC & 0,00035 & $0,31 \%$ & 0,00010 & $0,09 \%$ & 0,00046 & $0,40 \%$ \\
\hline Degree & 0,00001 & $0,01 \%$ & 0,00001 & $0,01 \%$ & 0,00002 & $0,02 \%$ \\
\hline $\mathrm{HND} / \mathrm{HNCT}$ & 0,00004 & $0,04 \%$ & $-0,00001$ & $-0,01 \%$ & 0,00003 & $0,02 \%$ \\
\hline $\mathrm{O} / \mathrm{CSE}$ & 0,00003 & $0,02 \%$ & $-0,00001$ & $-0,01 \%$ & 0,00002 & $0,01 \%$ \\
\hline No qualification & 0,00038 & $0,34 \%$ & $-0,00029$ & $-0,25 \%$ & 0,00010 & $0,08 \%$ \\
\hline Non-white & $-0,00001$ & $-0,01 \%$ & 0,00000 & $0,00 \%$ & $-0,00001$ & $-0,01 \%$ \\
\hline Year 1999 & & & $-0,00017$ & $-0,15 \%$ & $-0,00017$ & $-0,15 \%$ \\
\hline Intercept & & & 0,00824 & $7,24 \%$ & 0,00824 & $7,24 \%$ \\
\hline Total & 0,00364 & $3,20 \%$ & 0,00341 & $2,99 \%$ & 0,00705 & $6,19 \%$ \\
\hline Residual & & & & & 0,10676 & $93,81 \%$ \\
\hline Actual & & & & & 0,11381 & $100,00 \%$ \\
\hline CONC. INDEX & Hom. & $\begin{array}{l}\text { ontrib. } \\
\text { as } \%\end{array}$ & Het. & $\begin{array}{l}\text { ontrib. } \\
\text { as } \%\end{array}$ & Total & $\begin{array}{l}\text { ontrib. } \\
\text { as \% }\end{array}$ \\
\hline$\overline{\log (\text { income })}$ & 0,00724 & $55,49 \%$ & 0,00529 & $40,54 \%$ & 0,01254 & $96,03 \%$ \\
\hline Never married & $-0,00006$ & $-0,42 \%$ & $-0,00006$ & $-0,46 \%$ & $-0,00012$ & $-0,88 \%$ \\
\hline Divced., septed., or widwd. & 0,00236 & $18,05 \%$ & $-0,00074$ & $-5,70 \%$ & 0,00161 & $12,35 \%$ \\
\hline Children & 0,00016 & $1,23 \%$ & $-0,00017$ & $-1,29 \%$ & $-0,00001$ & $-0,07 \%$ \\
\hline Professional or managerial & 0,00021 & $1,59 \%$ & $-0,00040$ & $-3,08 \%$ & $-0,00019$ & $-1,49 \%$ \\
\hline Skilled & 0,00055 & $4,20 \%$ & $-0,00022$ & $-1,71 \%$ & 0,00032 & $2,49 \%$ \\
\hline Unskilled & $-0,00010$ & $-0,76 \%$ & 0,00004 & $0,31 \%$ & $-0,00006$ & $-0,45 \%$ \\
\hline Unemployed & 0,00044 & $3,39 \%$ & 0,00032 & $2,42 \%$ & 0,00076 & $5,82 \%$ \\
\hline Student or retired & $-0,00318$ & $-24,33 \%$ & 0,00120 & $9,19 \%$ & $-0,00198$ & $-15,14 \%$ \\
\hline Carer & 0,00026 & $2,02 \%$ & 0,00001 & $0,07 \%$ & 0,00027 & $2,09 \%$ \\
\hline Other SC & 0,00169 & $12,98 \%$ & 0,00118 & $9,07 \%$ & 0,00288 & $22,05 \%$ \\
\hline Degree & 0,00010 & $0,79 \%$ & $-0,00003$ & $-0,21 \%$ & 0,00008 & $0,58 \%$ \\
\hline $\mathrm{HND} / \mathrm{HNCT}$ & 0,00015 & $1,13 \%$ & 0,00004 & $0,31 \%$ & 0,00019 & $1,43 \%$ \\
\hline $\mathrm{O} / \mathrm{CSE}$ & 0,00001 & $0,09 \%$ & 0,00028 & $2,12 \%$ & 0,00029 & $2,22 \%$ \\
\hline No qualification & 0,00145 & $11,13 \%$ & 0,00006 & $0,45 \%$ & 0,00151 & $11,58 \%$ \\
\hline Non-white & 0,00000 & $-0,03 \%$ & 0,00005 & $0,41 \%$ & 0,00005 & $0,37 \%$ \\
\hline Year 1999 & & & 0,00043 & $3,31 \%$ & 0,00043 & $3,31 \%$ \\
\hline Intercept & & & $-0,00657$ & $-50,30 \%$ & $-0,00657$ & $-50,30 \%$ \\
\hline Total & 0,01130 & $86,54 \%$ & 0,00071 & $5,45 \%$ & 0,01201 & $92,00 \%$ \\
\hline Residual & & & & & 0,00105 & $8,00 \%$ \\
\hline Actual & & & & & 0,01305 & $100,00 \%$ \\
\hline
\end{tabular}


The "heterogeneous parameters contributions" component of the decomposition shows how heterogeneity in both the intercept and the slope coefficients modifies the contribution to inequality of the regressors. The figures in Table 3 show that heterogeneity in responses increases the Gini coefficient by $2.99 \%$ and the concentration index by $5.45 \%$. The impact of income is of particular interest. Heterogeneity in the income effect results in the Gini coefficient being smaller than what it would be if all demographic groups had the average income slope coefficient all else held equal. On the contrary, heterogeneity in the income effect results in the concentration index being greater than what it would be if all demographic groups had the average income slope coefficient all else held equal. In particular, the results in the table suggest that the concentration index would be $40.54 \%$ smaller if the marginal effect of income was homogeneous in the population. This empirical finding suggests that the demographic groups, as defined by birth cohort and gender, where income has a greater marginal impact on psychological well-being as measured by the GHQ' score enjoy a higher than average level of income.

An important contributor to income related health inequality is the incidence of divorce, separation or widowhood. Since this event is associated to a lower GHQ' score and there is pro-poor inequality in its distribution, it accounts for a $12.35 \%$ of the actual concentration index. However, this contribution would be larger if there was homogeneity in responses. The $-5.70 \%$ figure in the "heterogeneous contributions" column shows that those individuals for whom the (negative) association between this event and psychological well-being is stronger tend to enjoy a higher than average level of income. Thus the net contribution to income related health inequality is lower than what the $18.05 \%$ figure in the "homogeneous contributions" column shows. ${ }^{1}$ Another important contributor to the concentration index is the "other social class" indicator. Because belonging to this category is negatively associated to psychological well-being and because there is pro-poor inequality in the distribution of this demographic, this variable accounts for a $22.05 \%$ of income related inequality in psychological well-being. A substantial part of this contribution, 9,07., is due to

1 The estimates for the divorced/separated/widowed dummy variables for the youngest cohorts are affected by the fact that less than $0.25 \%$ of the corresponding samples fall within this category. We are grateful to one of the referees for pointing out that this could explain -despite the general pattern of negative impacts found for the rest of demographic groups and what one might intuitively expect- the positive (but not significant) point estimate for women in the 1976-1983 cohort. In order to gauge the potential effect of this counterintuitive result on the decomposition of the inequality indices, we have reestimated the model constraining the parameter for the youngest cohorts (of both women and men) to be equal to -0.95 (the corresponding parameter in the pooled OLS model) and re-calculated the inequality contributions. We find that the impact is not large, as the contribution of the heterogeneous components would be, respectively for the GINI and CI indices , $-0,017 \%$ and $6.1 \%$, and the counterparts to these figure in table 3 are $0,79 \%$ and $12,35 \%$. 
the heterogeneity of responses, since those individuals for whom the impact is greater in absolute value tend to have a lower than average level of income. A similar pattern is found in the contribution of unemployment, where heterogeneity of responses accounts for nearly one half of the overall $5.82 \%$ contribution to the concentration index. The net contribution of the student or retired status is made up of two conflicting components. Its "homogeneous contribution", $-24.33 \%$ of the overall CI, reflects that this demographic is on average associated to a greater GHQ' score, but there is pro-poor inequality in its distribution of this demographic. However, those for whom the effect is greater than average (men and women in the 1935-1944 cohort) tend to have a greater than average level of income and vice versa. Thus the "heterogeneous contribution" of this explanatory variable is positive.

It is noteworthy that the heterogeneity of the intercepts accounts for a large share, $-50,3 \%$, of the concentration index. Young cohorts (those born after 1954) would report, if there were no differences in neither covariates nor responses, a greater GHQ' score than older cohorts (except males in the oldest cohort). But these individuals tend to enjoy a lower than average level of income so this pattern of heterogeneity accounts for a $50,3 \%$ reduction in the concentration index.

\section{Summary and conclusion}

In this paper we have shown how the regression based methods for the decomposition of health inequality developed by Wagstaff et al. (2003) can be extended to incorporate individual heterogeneity in the responses of health to the explanatory variables. We have illustrated our proposal with an application to the measure of psychological well-being in the BHPS (waves 19911999). While this methodology is illustrated with an application for inequalities in health, it can be applied to other contexts where inequalities are relevant and an econometric model is used to explain the outcome variable of interest. A recent example outside health economics is Ferrer-iCarbonell and Van Praag (2003), who model income satisfaction and decompose its inequality in terms of a series of conditioning variables.

Allowing for heterogeneity in the responses of individuals' health to differences in socio-economic characteristics is one way in which the specification of regression functions may be improved. This improved fit means that a higher proportion of both overall and of income-related inequality can be attributed to the "explained" component in regression-based decompositions of Gini and concentration indices. The new decomposition method presented in this paper extends the work of Wagstaff et al. (2003) to show that the contribution of regressors can be further decomposed; the 
decomposition of the overall level of inequality distinguishes between the contribution of the level of inequality in the regressors, evaluated at the pooled level of the coefficients, and the contribution of heterogeneity in the coefficients around the pooled values. The interpretation of the new decomposition formula has a clear parallel with the use of Oaxaca (1973) decompositions of changes in inequalities over time or across countries.

The empirical results for the GHQ measure of psychological well-being suggest that there is an important degree of heterogeneity in the association of health to explanatory variables across birth cohorts and genders which, in turn, accounts for a substantial percentage of the inequality in observed health. A particularly interesting finding is that heterogeneity in the marginal effect of income accounts for $40.54 \%$ of the observed concentration index of the GHQ' psychological wellbeing score on income. Since reducing responsiveness of health to income differentials across groups is considered an important policy-lever for the purposes of eliminating socio-economic inequalities in health, this result illustrates the possibilities for application of the methodology presented in this paper and suggests that the heterogeneity of income elasticities should be investigated further. 


\section{References}

Bowling, A., 1991, Measuring health. A review of quality of life measurement scales. OUP, Milton Keynes.

Ferrer-i-Carbonell, A. and Van Praag, B., 2003, Income satisfaction inequality and its causes. Journal of Economic Inequality 1, 107-127.

Fleurbaey, M., 2004, Health, equity and social welfare. Mimeo, CATT, IDEP, Université de Pau et des Pays de l'Adour.

Fields, G. S., 2003, Accounting for income inequality and its change: A new method, with applications to the distribution of earnings in the United States. In S.W. Polachek (ed.) Worker Well being and Public Policy. Research in Labor Economics Series 22. Elsevier.

Gakidou, E, Murray, C., Frenk, J., 2000, Defining and measuring health inequality. Bulletin of the World Health Organisation, 78, 42-52.

Goldberg, D., Williams, P., 1988, A user's guide to the General Health Questionnaire. Nfer-Nelson, Windsor.

Hauck, K., Rice, N., 2003, Health mobility in the UK: a longitudinal analysis of psychological wellbeing. University of York, mimeo.

Heckman, J., 2001. Micro data, heterogeneity, and the evaluation of public policy: Nobel lecture, Journal of Political Economy, 109, 673-748.

Kakwani, N.C., 1980. Income Inequality and Poverty. Methods of Estimation and Policy Implications. Oxford University Press, Oxford.

Koenker, R., and Bassett, G., 1982. Robust tests for heteroscedasticity based on regression quantiles. Econometrica 50, 43-61.

Kolenikov, S. and Shorrocks A., 2005. A decomposition analysis of regional poverty in Russia. Review of Development Economics, 9, 25-46.

Lambert, P., 1993. The distribution and redistribution of income. A mathematical analysis. $2^{\text {nd }}$ Edition. Manchester University Press. Manchester.

Le Grand, J., 1989, An international comparison of ages-at-death. in J. Fox (ed.) Health inequalities in European countries. Gower, Aldershot.

Lerman, R.I., Yitzhaki, S., 1989. Improving the accuracy of estimates of Gini coefficients. Journal of Econometrics 42, 43-47.

Likert, R., 1952, A technique for the development of attitude scales. Educational and Psychological Measurement 12, 313-315.

Morris, S, Sutton, M., and Gravelle, H., 2003, Inequity and inequality in the use of health care in England. CHE Technical Paper Series, 27.

Oaxaca, R.L., 1973. Male-female wage differentials in urban labor markets. International Economic Review 14, 693-709. 
Rao, V.M., 1969, Two decompositions of concentration ratio, Journal of the Royal Statistical Society. Series A(General), 132, 418-425.

Shorrocks, A. 1999, Decomposition procedures for distributional analysis: An unified framework based on the Shapley Value. Manuscript. University of Essex.

Silber, J. 1988, On inequality before death and life table. Summary measures. Genus. 44, 25-39.

Taylor, M.F. (ed.) with Brice, J., Buck, N., and Prentice, E., 1998, British Household Panel Survey User Manual, University of Essex, Colchester.

Van Doorslaer, E. and Jones, A. 2003, Inequalities in self-reported health: validation of a new approach to measurement.. Journal of Health Economics 22, 61-87.

Van Doorslaer, E. and Koolman, X., 2004, Exploring the differences in income-related health inequalities across European countries. Health Economics, 13, 609-628.

Van Doorslaer, E., Wagstaff, A., Bleichrodt, H., et al, 1997. Income-related inequalities in health: some international comparisons. Journal of Health Economics 16, 93-112.

Wagstaff, A., van Doorslaer, E., 1994. Measuring inequalities in health in the presence of multiplecategory morbidity indicators. Health Economics 3, 281-291.

Wagstaff, A., van Doorslaer, E., Paci, P., 1989. Equity in the finance and delivery of health care: some tentative cross-country comparisons. Oxford Review of Economic Policy 5, 89-112.

Wagstaff, A., Paci, P., van Doorslaer, E., 1991. On the measurement of inequalities in health. Social Science and Medicine 33, 545-557.

Wagstaff, A, van Doorslaer, E., Watanabe, N., 2003. On decomposing the causes of health sector inequalities with an application to malnutrition inequalities in Vietnam, Journal of Econometrics 112, 207-223.

Weich, S., Lewis, G., Jenkins, S.P., 2001, Income inequality and the prevalence of common mental disorders in Britain. British Journal of Psychiatry 178, 222-227.

Wildman, J., 2003. Income related inequalities in mental health in Great Britain: analysing the causes of health inequality over time. Journal of Health Economics 22, 295-312 
Table A.1 Full regression estimates (robust standard errors in parentheses)

\begin{tabular}{|c|c|c|c|c|c|c|c|c|c|c|c|c|c|c|c|c|}
\hline & $\begin{array}{l}\text { Hom. } \\
\text { model }\end{array}$ & 1 & 2 & 3 & 4 & 5 & 6 & 7 & 8 & 9 & 10 & 11 & 12 & 13 & 14 & $\begin{array}{l}\text { Hom. Test } \\
\mathrm{F}(13,20258)\end{array}$ \\
\hline \multirow[t]{2}{*}{ Log(income) } & 0,516 & $-0,016$ & $-0,006$ & 0,308 & 0,337 & 0,486 & 0,423 & 0,873 & 0,614 & 0,669 & 0,826 & 0,599 & 0,585 & 0,325 & 0,431 & 2,15 \\
\hline & $(0,05)$ & $(0,18)$ & $(0,15)$ & $(0,13)$ & $(0,13)$ & $(0,17)$ & $(0,17)$ & $(0,18)$ & $(0,19)$ & $(0,22)$ & $(0,23)$ & $(0,25)$ & $(0,21)$ & $(0,23)$ & $(0,25)$ & \\
\hline \multirow[t]{2}{*}{ Never married } & $-0,174$ & 0,127 & $-0,380$ & 0,202 & $-0,111$ & $-0,359$ & $-0,537$ & $-0,403$ & 0,398 & $-0,282$ & 1,739 & $-0,147$ & $-0,493$ & 0,543 & $-0,639$ & 1,51 \\
\hline & $(0,09)$ & $(0,28)$ & $(0,31)$ & $(0,17)$ & $(0,16)$ & $(0,39)$ & $(0,33)$ & $(0,47)$ & $(0,55)$ & $(0,72)$ & $(0,63)$ & $(0,61)$ & $(0,60)$ & $(0,41)$ & $(0,58)$ & \\
\hline \multirow[t]{2}{*}{ Divced., septed., or widwd. } & $-0,952$ & 2,345 & $-23,384$ & $-1,473$ & $-2,482$ & $-1,442$ & $-1,661$ & $-0,953$ & $-0,842$ & $-1,759$ & $-0,216$ & $-0,633$ & $-0,255$ & $-0,361$ & $-0,339$ & 86,39 \\
\hline & $(0,11)$ & $(1,56)$ & $(0,67)$ & $(0,43)$ & $(0,50)$ & $(0,32)$ & $(0,44)$ & $(0,34)$ & $(0,43)$ & $(0,40)$ & $(0,53)$ & $(0,33)$ & $(0,38)$ & $(0,27)$ & $(0,31)$ & \\
\hline \multirow[t]{2}{*}{ Children } & 0,004 & 0,068 & 0,332 & 0,001 & $-0,082$ & $-0,022$ & $-0,048$ & 0,294 & 0,036 & 0,115 & $-0,021$ & $-0,052$ & $-0,353$ & 0,294 & 0,332 & 1,41 \\
\hline & $(0,03)$ & $(0,12)$ & $(0,09)$ & $(0,09)$ & $(0,10)$ & $(0,10)$ & $(0,09)$ & $(0,12)$ & $(0,12)$ & $(0,36)$ & $(0,27)$ & $(0,59)$ & $(0,44)$ & $(0,63)$ & $(0,51)$ & \\
\hline \multirow[t]{2}{*}{ Professional or managerial } & $-0,074$ & 0,547 & $-0,279$ & 0,031 & 0,145 & $-0,250$ & 0,006 & $-0,365$ & 0,380 & $-0,797$ & $-0,118$ & $-0,317$ & $-1,154$ & $-0,240$ & 0,402 & 1,12 \\
\hline & $(0,09)$ & $(0,44)$ & $(0,42)$ & $(0,20)$ & $(0,21)$ & $(0,24)$ & $(0,29)$ & $(0,27)$ & $(0,39)$ & $(0,36)$ & $(0,38)$ & $(0,70)$ & $(0,60)$ & $(2,83)$ & $(0,69)$ & \\
\hline \multirow[t]{2}{*}{ Skilled } & 0,419 & 0,274 & $-0,318$ & $-0,389$ & 0,114 & 0,179 & 0,374 & 0,051 & 0,969 & 0,720 & 0,636 & 1,465 & 0,443 & 1,738 & $-0,363$ & 1,37 \\
\hline & $(0,10)$ & $(0,47)$ & $(0,36)$ & $(0,28)$ & $(0,22)$ & $(0,32)$ & $(0,30)$ & $(0,37)$ & $(0,40)$ & $(0,49)$ & $(0,40)$ & $(0,87)$ & $(0,48)$ & $(1,11)$ & $(0,90)$ & \\
\hline \multirow[t]{2}{*}{ Other SC } & $-0,652$ & $-0,293$ & $-0,337$ & $-0,536$ & $-0,235$ & $-0,190$ & $-0,705$ & $-1,367$ & $-1,588$ & $-1,263$ & $-1,552$ & $-0,257$ & $-1,819$ & 0,023 & $-3,327$ & 3,05 \\
\hline & $(0,09)$ & $(0,26)$ & $(0,28)$ & $(0,24)$ & $(0,24)$ & $(0,25)$ & $(0,38)$ & $(0,30)$ & $(0,53)$ & $(0,39)$ & $(0,45)$ & $(0,57)$ & $(0,53)$ & $(1,10)$ & $(0,89)$ & \\
\hline \multirow[t]{2}{*}{ Unskilled } & 0,347 & $-0,917$ & $-0,587$ & 0,282 & $-0,186$ & 0,741 & $-0,024$ & 0,026 & 1,081 & 0,191 & 1,030 & 1,836 & 0,679 & 3,513 & $-1,273$ & 2,10 \\
\hline & $(0,15)$ & $(0,63)$ & $(0,40)$ & $(0,49)$ & $(0,38)$ & $(0,46)$ & $(0,52)$ & $(0,46)$ & $(0,53)$ & $(0,50)$ & $(0,87)$ & $(0,64)$ & $(0,75)$ & $(1,42)$ & $(1,15)$ & \\
\hline \multirow[t]{2}{*}{ Unemployed } & $-1,011$ & $-1,748$ & $-1,900$ & $-1,187$ & $-1,505$ & $-1,264$ & $-1,312$ & $-1,298$ & $-0,285$ & $-0,794$ & 1,084 & 0,449 & 0,891 & 1,523 & 5,447 & 6,44 \\
\hline & $(0,14)$ & $(0,58)$ & $(0,45)$ & $(0,34)$ & $(0,28)$ & $(0,56)$ & $(0,41)$ & $(0,57)$ & $(0,53)$ & $(0,64)$ & $(0,52)$ & $(0,91)$ & $(0,73)$ & $(2,12)$ & $(0,96)$ & \\
\hline \multirow[t]{2}{*}{ Student or retired } & 0,480 & $-0,015$ & $-0,094$ & 0,214 & 0,318 & 0,877 & $-0,106$ & 0,669 & $-0,639$ & 1,574 & 2,025 & 0,375 & 1,330 & 1,061 & 1,290 & 3,49 \\
\hline & $(0,09)$ & $(0,28)$ & $(0,26)$ & $(0,28)$ & $(0,27)$ & $(0,70)$ & $(0,82)$ & $(0,57)$ & $(0,78)$ & $(0,38)$ & $(0,40)$ & $(0,40)$ & $(0,33)$ & $(0,37)$ & $(0,79)$ & \\
\hline \multirow[t]{2}{*}{ Carer } & 0,029 & $-1,687$ & 0,048 & $-0,284$ & 0,525 & $-0,395$ & $-0,855$ & 0,471 & 0,644 & 0,880 & 3,921 & 0,178 & $-1,277$ & 0,888 & $-4,493$ & 5,06 \\
\hline & $(0,12)$ & $(0,68)$ & $(1,05)$ & $(0,27)$ & $(0,34)$ & $(0,27)$ & $(1,01)$ & $(0,37)$ & $(1,22)$ & $(0,39)$ & $(0,86)$ & $(0,50)$ & $(1,69)$ & $(0,38)$ & $(1,01)$ & \\
\hline \multirow[t]{2}{*}{ Degree } & 0,179 & 1,223 & $-0,928$ & 0,234 & $-0,137$ & 0,255 & $-0,209$ & $-0,065$ & $-0,680$ & $-0,349$ & 0,955 & $-0,461$ & $-1,002$ & 1,550 & $-0,770$ & 1,82 \\
\hline & $(0,11)$ & $(0,42)$ & $(0,53)$ & $(0,25)$ & $(0,23)$ & $(0,34)$ & $(0,33)$ & $(0,47)$ & $(0,42)$ & $(0,80)$ & $(0,56)$ & $(0,85)$ & $(0,76)$ & $(1,24)$ & $(0,85)$ & \\
\hline \multirow[t]{2}{*}{$\mathrm{HND} / \mathrm{HNCT}$} & 0,306 & 0,510 & $-0,840$ & 0,087 & $-0,248$ & $-0,004$ & 0,273 & 0,385 & 0,090 & 0,871 & 1,364 & $-0,083$ & $-1,257$ & 1,509 & 0,889 & 1,54 \\
\hline & $(0,14)$ & $(0,66)$ & $(0,55)$ & $(0,36)$ & $(0,34)$ & $(0,46)$ & $(0,42)$ & $(0,50)$ & $(0,52)$ & $(0,80)$ & $(0,64)$ & $(1,06)$ & $(0,53)$ & $(0,88)$ & $(0,77)$ & \\
\hline \multirow[t]{2}{*}{$\mathrm{O} / \mathrm{CSE}$} & 0,169 & 0,201 & 0,011 & $-0,274$ & $-0,120$ & $-0,045$ & 0,559 & 0,062 & 0,428 & 1,517 & 0,989 & $-0,709$ & $-1,541$ & 1,638 & $-0,981$ & 2,69 \\
\hline & $(0,09)$ & $(0,30)$ & $(0,27)$ & $(0,21)$ & $(0,21)$ & $(0,28)$ & $(0,26)$ & $(0,37)$ & $(0,36)$ & $(0,61)$ & $(0,44)$ & $(0,62)$ & $(0,55)$ & $(0,74)$ & $(0,71)$ & \\
\hline No qualification & $-0,278$ & 1,562 & 0,000 & $-1,381$ & $-0,294$ & $-1,178$ & 0,360 & $-0,089$ & 0,025 & 0,366 & 0,683 & $-1,197$ & $-1,576$ & 0,549 & $-0,548$ & 4,06 \\
\hline
\end{tabular}




\begin{tabular}{|c|c|c|c|c|c|c|c|c|c|c|c|c|c|c|c|c|}
\hline & $(0,11)$ & $(0,48)$ & $(0,48)$ & $(0,41)$ & $(0,32)$ & $(0,36)$ & $(0,32)$ & $(0,37)$ & $(0,38)$ & $(0,59)$ & $(0,42)$ & $(0,56)$ & $(0,44)$ & $(0,67)$ & $(0,60)$ & \\
\hline \multirow[t]{2}{*}{ Non-white } & $-0,080$ & $-0,809$ & $-0,797$ & $-0,061$ & $-0,269$ & $-0,377$ & $-0,348$ & 0,900 & 0,443 & $-1,515$ & $-1,581$ & 0,584 & $-0,978$ & $-0,549$ & $-2,751$ & 0,84 \\
\hline & $(0,11)$ & $(0,71)$ & $(0,63)$ & $(0,42)$ & $(0,36)$ & $(0,48)$ & $(0,55)$ & $(0,64)$ & $(0,52)$ & $(1,15)$ & $(1,20)$ & $(1,01)$ & $(1,01)$ & $(1,39)$ & $(3,26)$ & \\
\hline \multirow[t]{2}{*}{ 1993-1994 } & $-0,204$ & $-0,199$ & $-0,144$ & $-0,133$ & $-0,142$ & $-0,238$ & $-0,053$ & $-0,322$ & $-0,269$ & $-0,490$ & $-0,127$ & $-0,501$ & $-0,138$ & $-0,567$ & $-0,003$ & 1,10 \\
\hline & $(0,05)$ & $(0,49)$ & $(0,48)$ & $(0,16)$ & $(0,14)$ & $(0,15)$ & $(0,14)$ & $(0,15)$ & $(0,16)$ & $(0,18)$ & $(0,17)$ & $(0,17)$ & $(0,16)$ & $(0,16)$ & $(0,18)$ & \\
\hline \multirow[t]{2}{*}{ 1995-1998 } & $-0,375$ & $-1,174$ & $-0,628$ & $-0,552$ & $-0,581$ & $-0,599$ & $-0,648$ & $-0,560$ & $-0,069$ & $-0,410$ & $-0,082$ & $-0,634$ & 0,185 & $-0,500$ & 0,039 & 2,70 \\
\hline & $(0,05)$ & $(0,46)$ & $(0,49)$ & $(0,16)$ & $(0,14)$ & $(0,16)$ & $(0,15)$ & $(0,16)$ & $(0,17)$ & $(0,20)$ & $(0,18)$ & $(0,20)$ & $(0,18)$ & $(0,17)$ & $(0,19)$ & \\
\hline \multirow[t]{2}{*}{1999} & $-0,193$ & $-0,846$ & $-0,589$ & $-0,296$ & $-0,410$ & $-0,320$ & $-0,855$ & 0,089 & 0,119 & $-0,108$ & $-0,040$ & $-0,469$ & 0,104 & $-0,679$ & $-0,075$ & 2,11 \\
\hline & $(0,06)$ & $(0,48)$ & $(0,51)$ & $(0,19)$ & $(0,17)$ & $(0,18)$ & $(0,18)$ & $(0,21)$ & $(0,21)$ & $(0,24)$ & $(0,24)$ & $(0,25)$ & $(0,23)$ & $(0,23)$ & $(0,26)$ & \\
\hline Age & $(0,04)$ & & & & & & & & & & & & & & & \\
\hline \multirow[t]{2}{*}{ Age squared / 100} & 0,795 & & & & & & & & & & & & & & & \\
\hline & $(0,08)$ & & & & & & & & & & & & & & & \\
\hline \multirow[t]{2}{*}{ Age cubed / 100} & $-0,004$ & & & & & & & & & & & & & & & \\
\hline & $(0,00)$ & & & & & & & & & & & & & & & \\
\hline \multirow[t]{2}{*}{ Male } & 1,133 & & & & & & & & & & & & & & & \\
\hline & $(0,07)$ & & & & & & & & & & & & & & & \\
\hline Constant & 26,833 & 25,993 & 28,256 & 22,698 & 23,867 & 20,444 & 21,975 & 16,476 & 19,225 & 18,167 & 16,850 & 21,001 & 22,729 & 20,158 & 24,193 & 3,58 \\
\hline Reset. $\mathrm{F}(3, \mathrm{~N}-(\mathrm{k}+3))$ & 26,21 & 0,68 & 0,35 & 5,14 & 0,31 & 10,18 & 0,36 & 19,00 & 6,82 & 5,42 & 2,38 & 2,89 & 3,17 & 2,47 & 2,16 & \\
\hline $\mathrm{N}$ & 88155 & 3321 & 2893 & 9642 & 8908 & 9425 & 8323 & 8357 & 7054 & 5901 & 5269 & 5026 & 4341 & 5897 & 3798 & \\
\hline
\end{tabular}

